\title{
TYPICAL APPLICATIONS OF AIRBORNE LIDAR TECHNOLAGY IN GEOLOGICAL INVESTIGATION
}

\author{
Xiongwei Zheng, Chunlei Xiao* \\ China Aero Geophysical Survey\& Remote Sensing Center for Land and Resources, Beijing100083, China- \\ (12260746,45561247)@qq.com
}

Commission III, WG III/5

KEY WORDS: airborne light detection and ranging (LiDAR); surface subsidence; landslide; fault

\begin{abstract}
:
The technology of airborne light detection and ranging (LiDAR), also referred to as Airborne Laser Scanning, is widely used for high-resolution topographic data acquisition (even under forest cover) with sub-meter planimetric and vertical accuracy. This contribution constructs the real digital terrain model to provide the direct observation data for the landscape analysis in geological domains. Based on the advantage of LiDAR, the authors mainly deal with the applications of LiDAR data to such fields as surface land collapse, landslide and fault structure extraction. The review conclusion shows that airborne LiDAR technology is becoming an indispensable tool for above mentioned issues, especially in the local and large scale investigations of micro-topography. The technology not only can identify the surface collapse, landslide boundary and subtle faulted landform, but also be able to extract the filling parameters of collapsed surface, the geomorphic parameters of landslide stability evaluation and cracks. This technology has extensive prospect of applications in geological investigation.
\end{abstract}

\section{INTRODUCTION}

Airborne light detection and ranging (LiDAR) system is a multi-sensor system comprising three major time-synchronized components: a laser scanner unit, a Global Navigation Satellite System (GNSS) and Inertial Measurement Unit (IMU). Based on the laser pulse time-of-flight distance measurement, all three components together enable the direct derivation of the absolute position $(\mathrm{X}, \mathrm{Y}, \mathrm{Z})$ of each record reflection on the earth. Therefore, the system is widely used for high-resolution topographic data acquisition.

The technology of LiDAR with its direct determination of elevation is capable to retrieve terrain (i.e. Bare Earth) point measurements even under forest cover, allowing the generation of Digital Terrain Models (DTMs) with a high degree of automation, which has revolutionized the acquisition of elevation data by providing a tool for rapid, highly accurate and cost-effective data acquisition, relevant for regional and local geological applications: Features such as tectonic structures even if covered by vegetation could be evident by small local elevation changes in the range of decimeters (Cunningham, 2006; Arrow Smith, 2009), these minor changes in elevation can still be observed as the high vertical accuracy of LiDAR is not lost by rasterization; Several studies use LiDAR DTM to derive topographic signatures for characterizing land-slides (Mc Kean, J., 2004; Glenn, N. F., 2006) or automated mapping of landslides (Booth, A. M., 2009) even in forested areas (Van Den Eeckhaut, 2012) in order to create or update inventories; Similar studies have continued to improve the state-of-the-art in automated mapping of landslides (Tarolli, 2012; Berti, 2013), extraction of channel networks, identification of biotic signatures in landscape morphology (Roering et al., 2010), classification of marine terraces (Bowles and Cowgill, 2012), and characterization of alluvial fan surfaces (Staley, 2006; Volker, 2007); Besides object detection and mapping airborne LiDAR data are an essential input in various process simulation models in order to be able to predict or simulate scenarios of future events and risk estimation of hazards such as floods modeling processes (Cobby, 2003; Rufin Soler, 2008), debris flows (Wichmann, V., 2008; Conway, 2010), rockfall (Deparis , J., 2008; Lan, H. X., 2010) and avalanches (Schmidt , 2005; McColliste, 2009).

This paper presents studies in the geological investigation fields such as surface land collapse, landslide and fault structure extraction, using LiDAR data acquired by Leica ALS50-II airborne laser system and its standard products -DEM, to assess the ability of LiDAR technology on geological objects detection and interpretation.

\section{LIDAR DATA ANALYSIS}

Airborne LiDAR system sends out laser pulses that get backscattered by various objects (ground surface, vegetation, constructions etc.) and record the feedback signal. Objects in different elevations may be illuminated by the cone of light causing more than one echo that can be recorded by the sensor's receiver, usually displayed in the form of discrete point cloud.

The analysis of LiDAR data products starting with the 3D point cloud, possibly with full-wave-form attributes, can be grouped into (i) a direct use of data and information derived from LiDAR such as digital elevation model (DEM) and (ii) an indirect application of further refined data such as roughness parameters of land cover maps and hillshade maps etc. Basically, the direct input extracts information from the LiDAR observation (i.e. elevation and radiometric data), whereas the indirect integration is based on a prior abstraction and processing (e.g. classification and object detection).

A first step in Geological landform interpretation is the LiDAR data visualization. For example, 3D perspective views or DEM color-coded by height. Slicing or drawing profiles of the data helps to get a better impression of the surface such as in complex situations with mixed surface and object types. Deeper understanding is gained by visualizing derivatives such as slope, aspect and surface curvature or to colored drape information 
from optical sensors over the elevation data. Care has to be taken when adding ancillary data not acquired simultaneously in order to avoid misinterpretation caused by temporal differences in both datasets. Also differences in registration, accuracy, and resolution have to be taken into account if combining different data sets.

For applications in Geological landform analysis the separation of terrain echoes (i.e. bare Earth) and echoes on objects such as buildings and vegetation - called filtering - is of major importance. Various methods and approaches are published either working directly on the point cloud or on rasterized Digital Surface Model (DSM). An introduction to filtering and an overview of the most prominent approaches can be found in Pfeifer (Pfeifer, 2008). An overview of processing methods, analysis, and comparison of widely distributed software products and applications of digital elevation models is given by Hengl (Heng, 2009). Elevation model representing the geomorphological relevant surface can be characterized by landform classification providing input for applications in geological investigation. DTM is the basis for landform characterization and delineation. Landforms vary in their appearance which depends on the representation scale, makes the boundary definitions of regions vague and difficult to delineate. This turns landform classification into an ambiguous multi-resolution problem. In order to reach high automation for classification, object-based approaches are used frequently. They either work directly in the point cloud (object-based point cloud analysis - OBPA, Rut zinger, 2008) or in the derived rasterized models and images (object-based image analysis OBIA, Blaschke, 2010). These approaches can be combined or iteratively applied where first the input data is segmented into homogeneous areas to define patches of points or pixels, which represent a part of an object. Features describing segments can be either related to the statistical distribution of the point or pixel values and their geometrical and topological characteristics such as segment shape, size, and neighborhood relations. Originally coming from the field of land cover classification OBIA is also used for DTM extraction and geomorphological object classification.

\section{APPLICATIONS}

\subsection{Surface Land Collapse Survey}

The subsidence is one form of coal mine secondary geological calamity, it will make the environment worsening and endanger people's life and safety. Therefore, recognizing the actual range of surface subsidence includes important research and practical significance. The precise measurement of the collapse, fill volume, area and other data for the mine geological environment problems provide decision-making basis for engineering renovation. In this paper, coal dam region in Hunan province was taken as an example to ground collapse analysis using airborne LiDAR, in order to study the surface subsidence( under vegetation cover)information recognition and extraction.

In the study area, there are complex geological environment in mines, dense vegetation, scarp, housing and other complex features. What's more, as a result of hydrothermal condition is enough, and less human disturbance after the collapse, in the region, surface subsidence covered by dense vegetation. Shown in figure 1 (a) for optical image of the mining subsidence area (red of the location of the elliptical instructions to collapse). The figure shows that, due to the optical sensors can't penetrate the vegetation, hence collapse information can't be accessed from the optical remote sensing image. After field investigation, it can found that the fieldwork method is difficult to carry out in test zone, due to steep terrain and dense vegetation cover (shown in figure 1 (a)). A prominent advantage of airborne LiDAR compared to photogrammetry is the ability to derive to penetrate vegetation by "seeing" through small gaps in the canopy, make it possible to derive accurate DTM even in densely forested areas, providing a very detailed terrain description. Therefore, based on the DEM constructed by discrete ground point from LiDAR, the boundaries of the earth's surface subsidence area and not collapse can be interpreted clearly (as shown in figure 1 (b) of the red line), so as to identify the collapse range effectively, and through further GIS spatial analysis to obtain the parameters such as geometric center of the surface subsidence pit coordinates (projected coordinate system), area and perimeter (table 1).

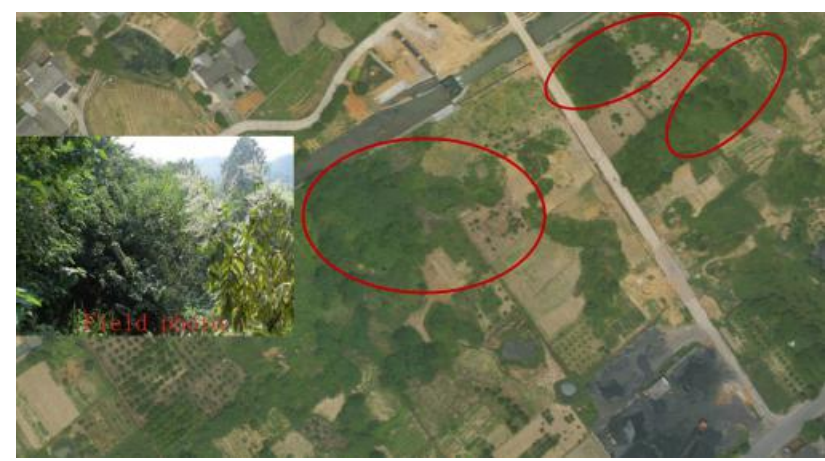

(a) image

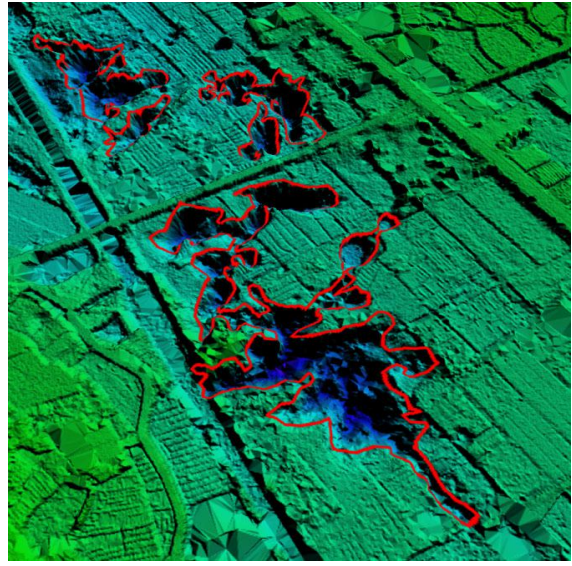

(b) DEM obtained by airborne LiDAR (the red line for the surface subsidence area and not collapse)

Figure 1.Subsidence area of coal dam covered with dense vegetation

\begin{tabular}{|l|c|}
\hline \multicolumn{2}{|c|}{ collapse pit } \\
\hline attribute name & attribute value \\
\hline perimeter / km & 1.345 \\
area $/ \mathrm{km}^{2}$ & 0.00755 \\
center_X/m & 638082.990 \\
center_Y/m & 318848.871 \\
center_Z/m & 44.15 \\
\hline
\end{tabular}

Table 1. Geometry information of subsidence pits

The advantage of surface subsidence investigation using airborne laser scanning system is that the obtained highprecision DEM , which is quicker and more accurate calculation sinkhole fill area and volume, provide important parameters for 
surface subsidence to implement project management. However, field geological investigation and measurement, are regularly difficult to accurate measure the subsidence pits fill area and volume parameters. In this paper, Triangular prism method is carried out to calculate the fill volume of surface subsidence, the basic principle is: (1) laser discrete point cloud on the ground constructed the irregular triangle net (TIN, figure 2 (left)), forming the three prism set about the calculation of earthwork terrain; (2) filtering out surface subsidence (pit) ground point, and then, using reserving ground points determined a zero plane (right) (figure 2)by surface fitting. (3) Finally, the superposition of two TIN structure obtained by the 2 on the surface of the corresponding volume of the irregular triangular structural unit clamp is the result of fill volume (table 2).
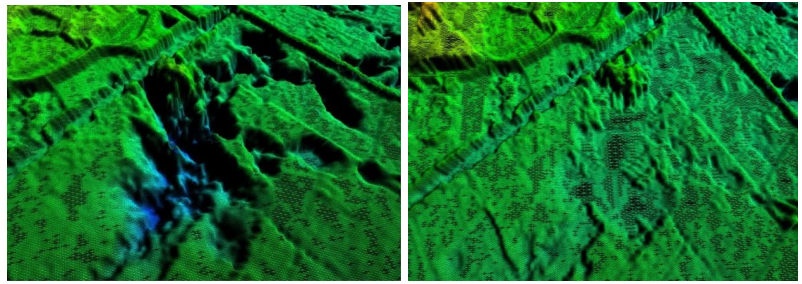

Fig.2 TIN constructed by ground data (left) and surface fitting(right)

\subsection{Landslides Detection And Characterization}

Airborne LiDAR permits an improvement in the landslides detection and characterization by creating accurate and precise high-resolution digital elevation model(HRDEM) in raster grids or TIN, which are $2.5 \mathrm{D}$ representations of the topography, or in true 3D point cloud with a high density. Taking Zhangjiawan landslides in three gorges region of China as an example, the method of landslide identification bases on HRDEM from LiDAR system is analyzed in this article.

The primary technique has been widely applied to detect and map landslides by optical remote sensing, makes use of image color difference or light shadow to identify terrain elevation mutations (such as slope sag, scratches, etc.). Although the resolution of image (figure 3) can achieve sub meter level, limited to a single light direction, it is difficult to identify the geomorphic features of landslide such as gully and boundary etc. in detail. For airborne LiDAR technology, the obtained bare earth point cloud data has the advantage to construct digital elevation model, which could depict the real topography, concluded micro morphological characteristics. And then, the hillshade can be derived through different azimuth settings based on DEM, with different illumination angle oblique hill shading set up by different azimuth to strengthen the micro morphological characteristics and terrain landform features, which facilitate to identify the boundary of landslide group.

Figure 4 shows that simulating different azimuth $\left(90^{\circ}, 135^{\circ}\right.$ and $180^{\circ}$ ), a series of hillshade images about Zhangjiawan landslides derived from DEM. Obviously, compared with optical image, hillshade maps based on LiDAR data can more clearly reflect the stereo configuration of landslides topography. Moreover, there are obvious differences in landslides local features expressed by shade relief images from different azimuth: Compared with the shade relief image under the illumination Angle $135^{\circ}$, these illumination Angle is $90^{\circ}$ and $180^{\circ}$ hillshade maps can more clearly reflect the linear features such as gully; The hillshade maps under azimuth angle $90^{\circ}$ and $180^{\circ}$, reflected different focus of the morphological characteristics, are able to complement each other. According to geomorphic features expressed by the hillshade maps under different azimuth angle, the boundary of Zhangjiawan landslides were delineated as shown in figure 5 (the red lines marking out the border of the landslide group), the landslide is composed of six secondary landslide.

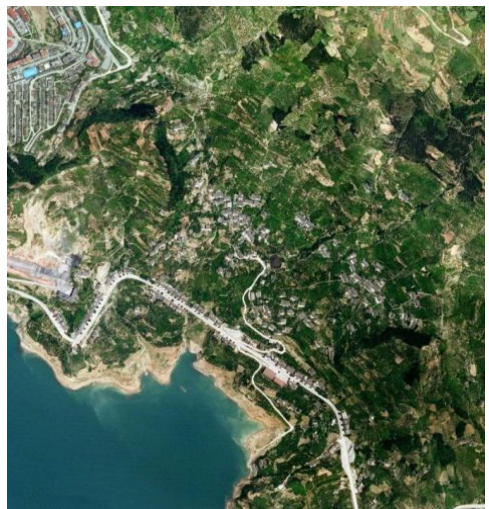

Fig.3 Ortho-photo of Zhangjiawan landslides

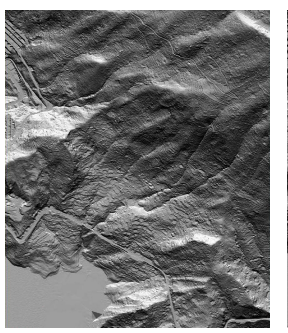

(a) Azimuth angle $90^{\circ}$

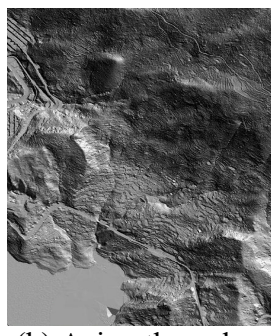

(b) Azimuth angle $135^{\circ}$

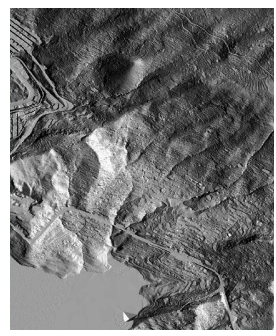

(c) Azimuth angle $180^{\circ}$
Fig.4 Hillshade maps of Zhangjiawan landslide

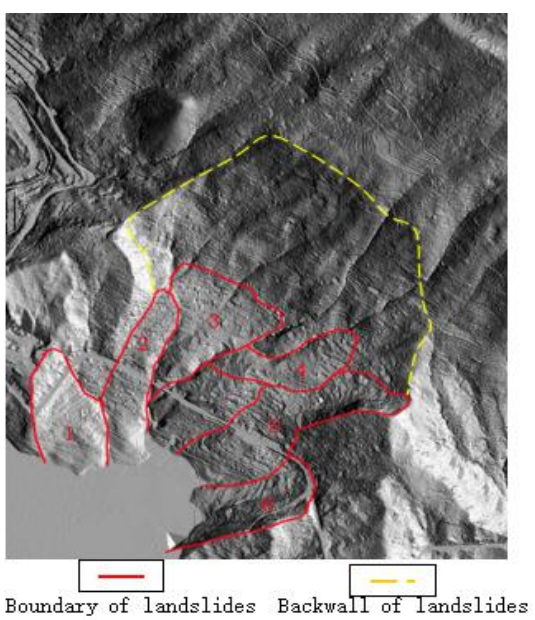

Fig.5 Boundary and back scarp of Zhangjiawan landslides(Azimuth angle $180^{\circ}$ )

\subsection{Fault detection}

ALS - derived DEM gives an accurate topography and permits to identify morphologies have significations in order to characterize the past fault activity. Study area located in Beiya mine lot in Yunnan province of China was selected to carry out the test on fault detection using LiDAR data. These data are 
very reliable with respect to height accuracy (root mean square error: $0.2 \mathrm{~m}$ ) and spot density (average density of laser spot: 2 $\left.\mathrm{pts} / \mathrm{m}^{2}\right)$.

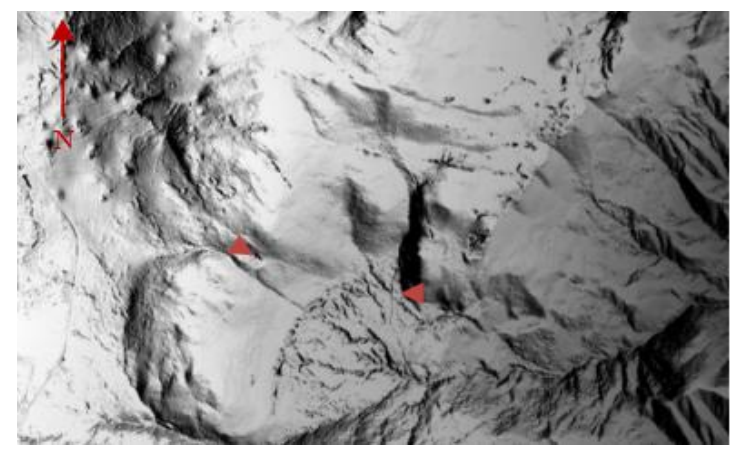

(a) Dimensional display by LiDAR data

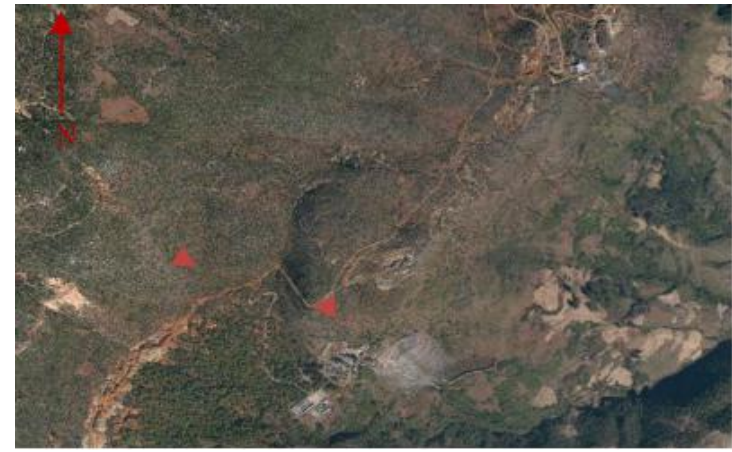

(b) Display by optical image

Fig.8 Display of micro-features of faults (Characteristic between the red arrow is fault broken terrain)

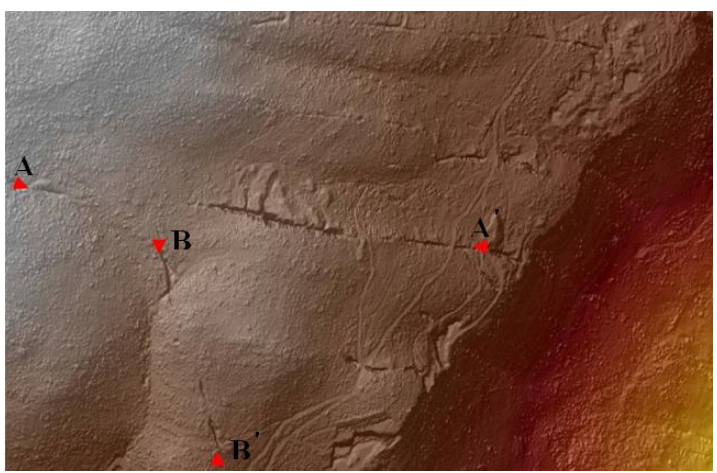

(a) Hillshade

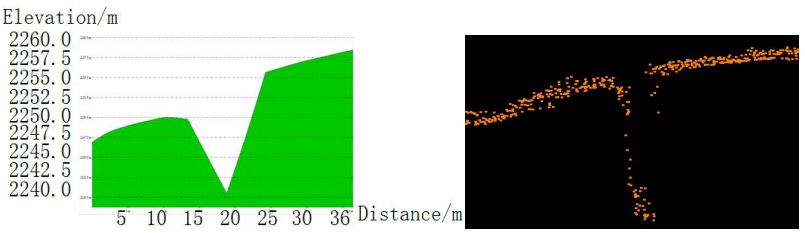

(b) DEM cross-section drawn (c)Discrete points cross-section drawn

Fig.9 Identification and micro-feature information of fissures

For early geomorphologists, field observations were central to investigate the fault fracture and local surface active fault zones in the scale of meters and centimeters, combined with surveying difficulties (poor line of sight and limited GPS coverage). LiDAR data can be depicted micro-topography meticulously, the derived hillshade can identify the location of the crack orientation towards nearly EW (AA) and NNW (BB) (figure 9 (a)). The LiDAR data is a form of discrete $3 \mathrm{~d}$ point clouds (figure 9c), makes a different with optics image connected relationship between pixels. Moreover, based on the LiDAR data profile information (figure 9 (b), (c)), the surface cracks information such as depth, length and geometric patterns can be determined, to provide the foundational data for fault detection quantitative analysis with different echoes.

Utilizing the filtering discrete ground points to constructed DEM of truly landscape, which has the high spatial resolution $(0.5 \mathrm{~m})$. This resolution reaches the scale demand for broken landscape identification. The shade relief derived from LiDAR DEM can realize true three-dimensional expression of the terrain bump tiny differences, succeeded to detect the surface fissuring and the displacement of fault as Fig.8(a) shown. However, compared with traditional optical remote sensing means the study found that it is difficult to identify the subtle fault broken terrain recognized from LiDAR data in optical image (figure $8 \mathrm{~b}$ ).

\section{CONCLUSIONS}

The airborne LiDAR (Light Detection and Ranging) technology can directly measure the elevation of the bare ground surface, construct Digital Elevation Model of true landscape, which could provide the foundational data for geological investigations. This paper demonstrates the applications in geological investigation such as surface land collapse, landslide and fault structure extraction for studying Earth surface landforms and points out the large potential of applications using LiDAR data for micro morphology of geological survey. LiDAR datasets are used in different processing levels, ranging from the original point clouds to the DEM, and also in different depths of integration into applications, starting with LiDAR derivatives (e.g. shaded relief map) assisting visual interpretation: Airborne LiDAR technology see through the vegetation on elevation to get the real 3D digital surface model (DEM), which is a reliable observation data to reveal the structure of the surface micro topography, which can recognize the surface subsidence under vegetation cover effectively, and extract quantitative elements such as filling area and volume of the surface subsidence, these elements can provide scientific basis for the comparative analysis about collapse development and engineering renovation in the complex landform area; The shaded relief map (hillshade) can simulate different illumination angle highlighting and strengthening the micro morphological characteristics to identify landslides effectively, that provides the real terrain observation data for landslides emergency; Compared with optical image, shaded relief map can reveal subtle fault broken terrain, the structural characteristics of small ups and downs, if do research in different echoes, the dynamic changes of the landform features can be depicted to provide a more effective technical methods for the high precision active faults structure research

\section{ACKNOWLEDGEMENTS}

This work was supported by Mineral resources exploitation \& environmental remote sensing monitoring project. (No. 121201203000160009).

\section{REFERENCES}

Booth, A. M., ROERING, J. J., 2009. Automated landslide mapping using spectral analysis and high resolution topographic 
data: Puget Sound lowlands, Washington, and Portland Hills, Oregon. Geomorphology, 109 (3), pp. 132-147.

Berti, M., Corsini, A., Daehne, A., 2013. Comparative analysis of surface roughness algorithms for the identification of active landslides. Geomorphology, 182(427),pp.1-18.

Bowles, C.J., Cowgill, E., 2012. Discovering marine terraces using airborne LiDAR along the Mendocino-Sonoma coast, northern California. Geosphere ,8 (8),pp. 386-402.

Deparis, J., Fricout, B., Jongmans, D., Vllemin, T., 2008. Combined use of geophysical methods and remote techniques for characterizing the fracture network of a potentially unstable cliff site (the "Roche du Midi", Vercors massif, France). $J$. Geophys. and Engineer, 5 (2), pp. 147-157.

Gleenn, N. F., Strutker, D. R., Chadwick, D. J., Thackray, G. D., 2006. Analysis of LiDAR-derived topographic information for characterizing and differentiating landslide morphology and activity. Geomorphology, 73 (1-2) pp. 131-148.

Hengl, T., Reuter, H., 2009. Geomorphometry Concepts, Software, Applications. Elsevier, pp. 796.

Mckean, J., Roering, J., 2004.Objective landslide detection and surface morphology mapping using high-resolution airborne laser altimetry. Geomorphology, 57 (3-4), pp. 331-351.

Lan, H. X., Mertin, C. D., Zhou, C. H., Lim, C. H., 2010. Rockfall hazard analysis using LiDAR and spatial modeling. Geomorphology, 118 (1-2), pp. 213-223.

Mccollister, C. M., Comey, R. H., 2009. Using LiDAR (Light Distancing And Ranging) data to more accurately describe avalanche terrain. Proc. International Snow Science Workshop, pp. 117-119.

Pfeifer, N., Mandlburger, G., 2008. LiDAR data filtering and DTM generation.Topographic laser ranging and scanning: Principles and processing, pp. 307-334.

Rufin Soler, C., Hequette, A., Gardel, A., 2008. Assessing the vulnerability of coastal lowlands to marine flooding using LiDAR data, Sangatte coastal dunes, northern France. Z., Geomorph. Suppl, 52 (3), pp.195-211.

Rutzinger, M., Hofle, B., Hollaus, M., 2008. Object-based point cloud analysis of fullwave form airborne laser scanning data for urban vegetation classification. Sensors, 8 (8), pp. 4505-4528.

Staley, D.M., Wasklewicz, T.A., Blaszczynski, J.S., 2006.

Surficial patterns of debris flow deposition on alluvial fans in Death Valley, CA using airborne laser swath mapping data. Geomorphology, 74 (1), pp.152-163.

Schmidt, R., Heller, A., Sailer, R., 2005.Vergleich von Laser scanning mit herkommlichen Hohendaten in der dynamische Lawinensimulation mit SAMOS. Internationale Geodatische Woche Obergurgl, Wichmann, pp.131-140.

Tarolli, P., Sofia, G., Dalla Fontana, G., 2012. Geomorphic features extraction from high resolution topography: landslide crowns and bank erosion. Natural Hazards, pp.1-19.

Van Den Eeckhaut, M., Kerle, N., Poesen, J., Hervás, J., 2012. Object-oriented identification of forested landslides with derivatives of single pulse LiDAR data. Geomorphology, $173-$ 174(9), pp. 30-42.

Volker, H., Wasklewicz, T., Ellis, M., 2007. A topographic fingerprint to distinguish alluvial fan formative processes. Geomorphology, 88 (1), pp. 34-45.

Wichmann V., Rutzinger, M., Vetter, M., 2008. Digital terrain model generation from airborne laser scanning point data and the effect of grid-cell size on the simulation results of a debris flow model. Hamb. Beitr. Phys. Geogr. und Landschaftsökol, 19, pp. 103-113.

Revised March 2018 